\title{
Prevalence of burnout syndrome among Italian volunteers of the Red Cross: a cross-sectional study
}

\author{
Francesco CHIRICO ${ }^{1,2 * a}$, Pietro CRESCENZO ${ }^{3 * a}$, Angelo SACCO ${ }^{1,4}$, Matteo RICCÒ ${ }^{5}$, \\ Serena RIPA ${ }^{6}$, Gabriella NUCERA ${ }^{7}$ and Nicola MAGNAVITA ${ }^{1,8}$ \\ ${ }^{1}$ Post-graduate School of Occupational Health, Università Cattolica del Sacro Cuore, Italy \\ ${ }^{2}$ Health Service Department, State Police, Ministry of Interior, Italy \\ ${ }^{3}$ Italian Red Cross Voluntary Military Corp, Psychological Activities Unit (NAP), Ministry of Defense, Italy \\ ${ }^{4}$ Local Healthcare Unit Roma 2, Italy \\ ${ }^{5}$ Dipartimento di Prevenzione, AUSL-IRCCS di Reggio Emilia, Italy \\ ${ }^{6}$ Centro la Famiglia Onlus, Italy \\ ${ }^{7}$ Department of Emergency, Fatebenefratelli Hospital, ASST Fatebenefratelli and Sacco, Italy \\ ${ }^{8}$ Department of Woman/Child \& Public Health, Fondazione Policlinico A. Gemelli IRCCS, Italy
}

Received November 29, 2020 and accepted January 14, 2021

Published online in J-STAGE January 20, 2021

\begin{abstract}
Burnout syndrome (BOS) is a work-related constellation of symptoms characterized by emotional exhaustion, depersonalization, and personal accomplishment. A cross-sectional survey was performed to study the prevalence of BOS among a randomly selected sample of 280 Italian Red Cross volunteers. A socio-demographic questionnaire and the Maslach Burnout Inventory (MBI)HSS were used to collect data. 241 volunteers participated (response rate: $86.1 \%$ ). A significant proportion of the workers had BOS subscale scores in the highest tertile: emotional exhaustion $8.0 \%$, depersonalization $35.9 \%$ and perceived lack of accomplishment $23.5 \%$, respectively. Volunteers in emergency care reported higher levels of emotional exhaustion $(p=0.004)$ and depersonalization $(p=0.001)$, and lower level of personal accomplishment $(p=0.042)$ than volunteers engaged in nonhealthcare social and administrative duties. These findings support the opportunity of a set of administrative, organizational and individual preventive interventions for emergency volunteers' mental health.
\end{abstract}

Key words: Burnout syndrome, Emergency care, Mental health, Red Cross, Volunteers

\section{Introduction}

Burnout syndrome (BOS) is a work-related condition that has been conceptualized as resulting from chronic workplace stress that has not been successfully managed ${ }^{1)}$,

*To whom correspondence should be addressed.

E-mail: francesco.chirico@unicatt.it; pietro.crescenzo@cm.cri.it

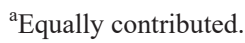

(C)2021 National Institute of Occupational Safety and Health which occurs in professionals frequently and/or severely exposed to crises and high-pressure situations, shift and overnight work, erratic work schedule, and stressful workloads ${ }^{2-5)}$, mainly including healthcare workers, and helping professions (i.e. as policemen and firefighters) ${ }^{6-11)}$. Since 2001, the three dimensions of BOS have been described as "exhaustion" (i.e. the feeling of not being able to offer any more of oneself at work), "cynicism" (i.e. a distant attitude towards work, clients and/or colleagues), and "inefficacy" (i.e. the feeling of not performing tasks adequately) ${ }^{7,12,13)}$. 
BOS has been especially studied among healthcare professionals ${ }^{14-18)}$, and available figures suggest that, even before the ongoing COVID-19 pandemic, it may affect more than half of practising physicians in the USA ${ }^{19)}$. Because of its potential impact on healthcare services, including poorer quality of care, professional mistakes, absenteeism, intention to give up the profession, and abandonment, physician burnout has been defined as a "global crisis"19).

Among the helping professions, first aid volunteers (FAVs) are a category of workers often overlooked with respect to the risk of developing burnout. In particular, those employed in ambulance service have a continuous contact with ill or suffering people, with resulting risk of developing "compassion fatigue", i.e. a condition characterized by emotional and physical exhaustion leading to a diminished ability to empathize or feel compassion for others ${ }^{4,5)}$.

FAVs face health and safety risks in order to assist in medical emergencies, motor vehicle incidents, building and wild-land fires, hazardous material spills, crimes and public disturbances, search and rescue ${ }^{20,21)}$. Moreover, they are among the first responders to basic needs in case of natural and man-made disasters, in support of population that needs clean water, shelter, food assistance and protection. Alongside military health care workers, public health service workers, and state, local, and volunteers, FAVs therefore play an important role in protecting citizens in the aftermath of disasters, being not spared by a wide range of mental health consequences such as posttraumatic stress disorders (PTSD), depression, anxiety, acute stress, and particularly $\mathrm{BOS}^{22)}$. Indeed, FAVs are not spared by the rising threat of workplace violence, a significant effector eliciting job burnout ${ }^{23-29)}$. Among FAVs, ambulance workers are particularly exposed to verbal/ psychological violence during their duties, and this risk factor has been associated with high level of burnout ${ }^{30,31)}$, with a resulting increased risk for critical incidents ${ }^{32,33)}$.

Even though BOS has been extensively characterized in emergency healthcare personnel ${ }^{34-42)}$, research on FAVs is relatively scarce, and evidence is somewhat conflicting, particularly for Italian personnel. For instance, a study on a small sample of Italian Red Cross volunteers did not list BOS as a major problem ${ }^{42)}$, and two Italian studies, including a little group of ambulance driver-rescuers, reported inconsistent findings ${ }^{43,44)}$. Eventually, another study on a larger but regional-based sample (i.e., 2,361 FAVs from the Sicily Region alone) of ambulance driverrescuers found a BOS prevalence of $29.8 \%{ }^{45}$.

The aim of this research was therefore to study the prevalence of BOS in FAVs of the Italian Red Cross, then comparing the levels of the three BOS sub-dimensions between FAVs engaged in social activities and those engaged in emergency care in order to identify their potential predictors.

\section{Subjects and Methods}

\section{Study design and setting}

The present cross-sectional survey was performed in April-May 2019 among volunteer members of ten local committees of the Red Cross in Salerno, Campania, Southern Italy, which is the second most populous city in Campania region (Total area 4,954.16 km²; with 1,092,779 inhabitants according to 2019 census), with a total of around 2,500 FAVs active at the time of the survey (2019).

The Italian Red Cross (in Italian: Croce Rossa Italiana; CRI) is among the original founding members of the International Committee of the Red Cross in 1919 and includes around 11,590 no profit associations for over 400,000 volunteers $^{46}$. Service as FAVs is deeply grounded within the Italian healthcare system. In facts, while the International Committee of the Red Cross mainly ensures humanitarian protection and assistance for victims of war and other situations of violence, CRI alongside other organizations for voluntary assistance (in Italian: Pubblica Assistenza or Misericordia), supports the Italian National Health Service also for daily medical emergencies, including ambulance services and first aid activities.

Despite their non-medical status, FAVs of the Italian Red Cross are medically trained personnel. Their training path is known as MTAR (Medical Transport and Ambulance Rescue) with the following basic requirements: a) being $\geq 18$ yr-old; b) having completed a training course including cardiopulmonary resuscitation (CPR) and First Aid rules; c) having received a formal formation course on health and safety in the workplace according to Italian National Law (i.e. Legislative Decree No. 81 of April 9th, 2008); and d) fulfilling psycho-physical requirements for ambulance service, as assessed by a special commission of medical and psychologist specialists. Formal and professional requirements of FAVs are periodically updated, as qualification as FAVs requires a periodical retraining. Even though FAVs do not receive a formal salary from CRI and/or Italian National Health Service, they have to guarantee from 2 to 20 shifts of work per month. Even though personal working shifts depend on the type of service provided, they usually face long-hours and tiring shift work ${ }^{47)}$. 


\section{Study population, sampling and data collection}

A total of $280 \mathrm{FAVs}$ were randomly selected from all volunteers of the CRI committee of Salerno. Inclusion criteria were: having a civilian background; performing either administrative or healthcare assistance tasks; having accomplished initial qualification.

\section{Ethical aspects}

The study protocol was approved by the Local Board of the Organism with internal protocol n.146/29.02.12. Moreover, an informed consent from each study subject to participate in the study was obtained before the start of work with assurance of confidentiality and anonymity of the data, according to ethical principles for medical research involving human subjects ${ }^{48)}$.

Subjects were invited personally by the investigator (psychologist) and they were asked to participate voluntarily with a full right to withdraw from the study. Our study was conducted in accordance with the ethical standards of the Declaration of Helsinki (2008).

\section{Study instruments}

An ad hoc descriptive questionnaire form was prepared by the researchers regarding socio-demographic and occupational characteristics. Sociodemographic data (age, sex and education) and information on employment situation, including years of experience, type of work (driving ambulance with rescue tasks $v s$ ordinary jobs) was collected.

To survey burnout syndrome, the Maslach Burnout Inventory (MBI)-HHS was used. MBI, which is the most commonly used tool to diagnose burnout, was developed by Maslach and Jackson ${ }^{6}$ and adapted in Italy by Sirigatti and Stefanile ${ }^{49)}$ to healthcare workers. With this inventory, the burnout situation was assessed through three sub-dimensions: Depersonalization (DP); Emotional Exhaustion (EE), and Personal Accomplishment (PA). The MBI is a 22-item self-completed questionnaire with the following subscales: 'EE' (9 items) measures feelings of being emotionally overextended and exhausted by one's work. "DP" (5 items) measures an unfeeling and impersonal response toward recipients of one's service, care treatment, or instruction. "PA" (8 items) measures feelings of competence and successful achievement in one's work (Mind Garden. com). All given answers are related to a 7-point Likert scale ranging from 0 (never) to 6 (every day) to express how frequently a person experiences the dimensions of burnout. These subscales are considered "high", "average", or "low" according to predetermined cut-off scores based on normative data. Scores are considered "high" if they are in the upper third of the normative distribution, "average" if they are in the middle one, "low" if they are in the lower third. Each subscale score is separately calculated; higher mean scores for DP and EE subscales and lower mean scores on the PA subscale correspond to a higher degree of burnout. The Italian validation of the questionnaire established the following ranges: high $\mathrm{EE}>24$, DP $>9, \mathrm{PA}>37$; average $\mathrm{EE}=15-23, \mathrm{DP}=4-8, \mathrm{PA}=30-36$; low $\mathrm{EE}<14, \mathrm{DP}<3, \mathrm{PA}<29$. The Italian normative sample of 748 Italians working in the healthcare professions gave $\mathrm{EE}=20.18 \pm 11.29 ; \mathrm{DP}=7.03 \pm 5.9 ; \mathrm{PA}=32.52 \pm 8.66^{50)}$.

In literature, there is no accepted standard definition for measuring burnout as a binary variable and the ideal approach is to use the individual domain scores as continuous data ${ }^{50)}$. For this reason, in this study we dichotomized the scores in the lower third and in the high/middle third, where a manifestation of burnout to be present in a respondent if the specific MBI subscore for that manifestation would have placed the respondent into the high/middle category.

Cronbach's $\alpha$ coefficient was used to test the internal consistency reliability for each MBI subscale. Authors calculated the Cronbach's alpha coefficients of the sub-scales as 0.83 for EE, 0.72 for PA and 0.65 for DP.

\section{Statistical analyses}

A descriptive analysis was undertaken to determine the characteristics of the study participants. Continuous data were reported as a mean or standard deviation, whereas categorial data were reported as a number or percentage. Univariate comparisons between participants performing emergency duties vs. social/administrative ones were initially performed by means of chi squared test (with Yates correction) for dichotomous variables, while continuous variables were assessed by means of Student's $t$-test for unpaired data. Similarly, for each dimensions of burnout the differences in sociodemographic characteristics were initially assessed through by means of Student's t-tests (with Bonferroni's correction for multiple comparisons). A two-ways Analysis of Variance (ANOVA) including both sociodemographic characteristics and work-related characteristics was then modeled for the three BOS dimensions, each one separately.

Eventually, in order to assess the impact of sociodemographic and work-related characteristics on BOS dimensions, a multiple linear regression was then modeled, calculating correspondent B regression coefficients with $95 \%$ confidence interval (CI) and the Nagelkerke's $\mathrm{R}^{2}$ for the outcome variable represented by the specific dimensions 
of burnout (i.e., EE, DP, PA). We opted for an "a priori" model that included as independent variables all factors assessed in univariate analysis (i.e., age, sex, seniority as emergency professional, education achievement). Two distinctive models were calculated, including all the sample as a whole, and only participants performing emergency duties.

Analyses were performed by means of IBM SPSS Statistics, version 25.0 (IBM Corp., Armonk, NY, USA) R (version 3.6.1; R Core Team, 2017. R: A language and environment for statistical computing. R Foundation for Statistical Computing, Vienna, Austria. URL https://www. R-project.org/), and RStudio (version 1.2.5019) software by means of car package (version 3.0-10). Significance level was set at $p<0.05$ for all calculations.

\section{Results}

The final study sample included a total of 241 participants (participation rate of $86.1 \%$; Fig. 1), with a mean age of $36.67 \pm 14.14$ years (actual range 18 to 73 ), and $57.7 \%$ of them were female.

As shown in Table 1, 162 out of 241 participants (i.e., $67.2 \%$ ) had emergency duties (i.e., ambulance drivers and first aid responders). Nearly half of them (49.6\%) reported more than $6 \mathrm{yr}$ of seniority. Remaining participants (32.8\%) engaged in social and administrative jobs were significantly younger (i.e., $27.46 \pm 12.21 \mathrm{yr}$ of age vs. $36.67 \pm 14.14, p<0.001$ ), and exhibited a generally lower educational achievement (i.e., $6.3 \%$ with a university-level degree compared to $15.4 \%$ among personnel performing emergency duties, $p=0.041$ ).

Overall, estimates for EE, FP and PA were $5.29 \pm 7.06$, 3.51. \pm 4.16 , and $36.37 \pm 8.96$, respectively, with 11 participants $(4.6 \%)$ having high likeliness of BOS status, all of them from ambulance personnel $(p=0.041)$. Corresponding subscale thresholds for medium-high burnout, subscale prevalence values were $8.7 \%$ for EE, $37.6 \%$ for DP, and $40.2 \%$ for PA. Ambulance personnel exhibited higher values of $\mathrm{EE}(6.04 \pm 8.02$ v. $3.76 \pm 4.11, p=0.004)$, and DP $(3.93 \pm 4.43$ vs. $2.66 \pm 3.39, p=0.015)$, while the PA dimension scored lower values in this subset compared to administrative / social personnel (34.73 \pm 8.32 vs. 37.16 $\pm 9.17, p=0.048$ ).

Comparisons of the sub-dimensions scores (Table 2) enlightened higher EE estimates in people having longer service in emergency settings $(8.15 \pm 10.56$ vs. $4.46 \pm 5.78$, $p=0.033)$ and reporting higher education level $(10.37 \pm 1.89$ vs. $4.79 \pm 6.33, p=0.045$ ). In both cases, when focusing on FAVs performing emergency duties, the differences were not significant ( $\mathrm{p}=0.083$, and $p=0.077$, respectively).

DP was higher in women (3.96 \pm 4.56 vs. $2.90 \pm 46$, $p=0.41$ ), and the difference remained appreciable in the subset of participants with emergency duties $(4.56 \pm 4.93$

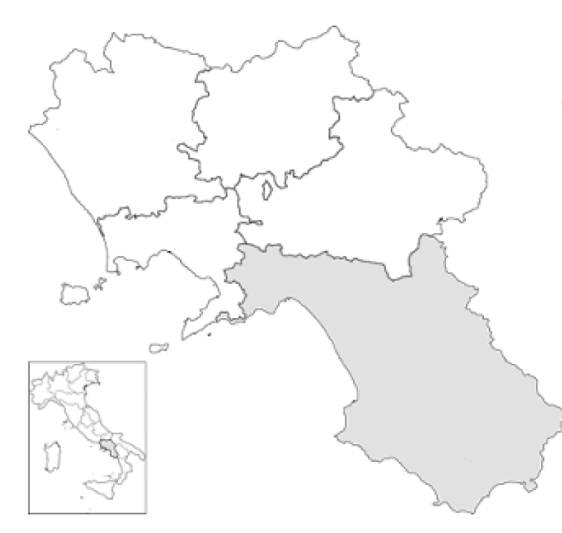

Salerno Province Total area 4,954.16 $\mathrm{km}^{2}$ $1,092,779$ inhabitants (2019 census)
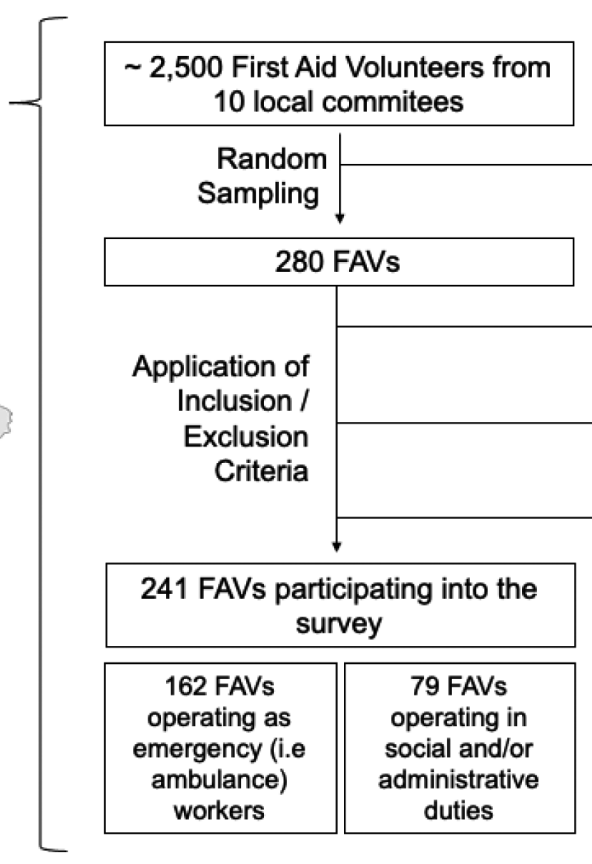
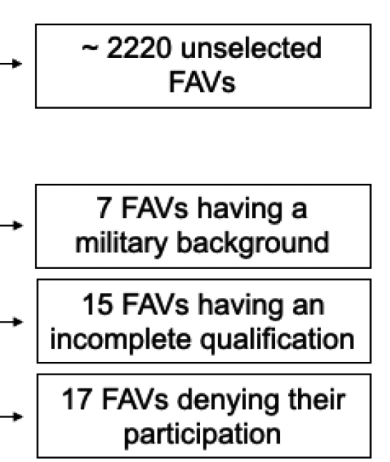

participation

Fig. 1. Selection process of the study participants. 
Table 1. Characteristics of 241 First Aid Volunteers (FAV) participating into the study on burnout syndrome (Salerno Province, Southern Italy, 2019)

\begin{tabular}{|c|c|c|c|c|}
\hline \multirow[b]{2}{*}{ Variables } & \multirow[b]{2}{*}{$\begin{array}{l}\text { Total Sample } \\
(\text { No. } 241, \%)\end{array}$} & \multicolumn{3}{|c|}{ Activities performed as FAV } \\
\hline & & $\begin{array}{l}\text { Emergency duties } \\
(\text { No.162, \%) }\end{array}$ & $\begin{array}{c}\text { Administrative / } \\
\text { Social jobs } \\
(\text { No.79, \%) }\end{array}$ & $p$ value \\
\hline Gender & & & & 0.904 \\
\hline Males & $102,42.3 \%$ & $69,42.6 \%$ & $33,41.8 \%$ & \\
\hline Females & $139,57.7 \%$ & $93,57.4 \%$ & $46,58.2 \%$ & \\
\hline Age group & $33.65 \pm 14.19$ & $36.67 \pm 14.14$ & $27.46 \pm 12.21$ & $<0.001$ \\
\hline $18-35 \mathrm{yr}$ & $141,58.5 \%$ & $81,50.0 \%$ & $60,75.9 \%$ & \\
\hline $35 \mathrm{yr}$ of more & $100,41.5 \%$ & $81,50.0 \%$ & $19,24.1 \%$ & \\
\hline Educational achievement & & & & 0.041 \\
\hline $\begin{array}{r}\text { Primary school } \\
\text { (i.e. }<9 \mathrm{yr} \text { of formal education) }\end{array}$ & $58,24.1 \%$ & $33,20.4 \%$ & $25,31.6 \%$ & \\
\hline $\begin{array}{r}\text { High school } \\
\text { (i.e. } 9 \text { to } 14 \text { yr of formal education) }\end{array}$ & $153,63.5 \%$ & $104,64.2 \%$ & $49,62.0 \%$ & \\
\hline $\begin{array}{r}\text { University } \\
\text { (i.e. }>14 \text { yr of formal education) }\end{array}$ & $30,12.4 \%$ & $25,15.4 \%$ & $5,6.3 \%$ & \\
\hline Seniority in emergence duties & & $8.01 \pm 6.88$ & & $<0.001$ \\
\hline$<1 \mathrm{yr}$ & $79,32.8 \%$ & $0,-$ & $79,100 \%$ & \\
\hline $1-5 \mathrm{yr}$ & $82,34.0 \%$ & $82,50.6 \%$ & N/A & \\
\hline $6-10 \mathrm{yr}$ & $33,13.7 \%$ & $33,20.4 \%$ & $\mathrm{~N} / \mathrm{A}$ & \\
\hline $11-15 \mathrm{yr}$ & $17,7.1 \%$ & $17,10.5 \%$ & N/A & \\
\hline Over $15 \mathrm{yr}$ & $30,12.4 \%$ & $30,18.5 \%$ & N/A & \\
\hline Burnout sub-dimensions & & & & \\
\hline Emotional exhaustion (EE) & $5.29 \pm 7.06$ & $6.04 \pm 8.02$ & $3.76 \pm 4.11$ & 0.004 \\
\hline $\begin{array}{r}\text { Emotional exhaustion (EE), } \\
\text { Medium-high level vs. low level }\end{array}$ & $21,8.7 \%$ & $19,11.7 \%$ & $2,2.5 \%$ & 0.033 \\
\hline Depersonalization (DP) & $3.51 \pm 4.16$ & $3.93 \pm 4.43$ & $2.66 \pm 3.39$ & 0.015 \\
\hline $\begin{array}{r}\text { Depersonalization (DP), } \\
\text { Medium-high level vs. low level }\end{array}$ & $93,38.6 \%$ & $71,43.8 \%$ & $22,27.8 \%$ & 0.025 \\
\hline Personal accomplishment (PA) & $36.37 \pm 8.96$ & $34.73 \pm 8.32$ & $37.16 \pm 9.17$ & 0.048 \\
\hline $\begin{array}{r}\text { Personal accomplishment (PA), } \\
\text { Medium-high level vs. low level }\end{array}$ & $97,40.2 \%$ & $58,35.8 \%$ & $39,49.4 \%$ & 0.061 \\
\hline Likeliness of burnout & $11,4.6 \%$ & $11,6.8 \%$ & $0,-$ & 0.041 \\
\hline
\end{tabular}

vs. $3.07 \pm 3.50, p=0.025$ ), while its was not among participants performing administrative/social jobs $(2.74 \pm 3.42$ vs. $2.55 \pm 3.40, p=0.804)$, and also the ANOVA ruled out a significant difference $(p=0.253)$.

Again, length of service was associated with higher score among people performing emergency duties for more than $10 \mathrm{yr}$ when compared to other participants (5.37 \pm 5.15 vs. $3.08 \pm 3.77, p=0.006)$, and the difference remained significant in the subset of emergency workers $(p=0.020)$. Eventually, higher PA were scored among FAVs of female gender $(38.15 \pm 8.43$ vs. $35.06 \pm 9.13, p=0.007)$, and particularly when focusing on emergency workers ( $39.67 \pm 7.94$ vs. $35.30 \pm 9.60, p=0.002)$, while the correspondent score for participants performing administrative and/or social jobs was quite similar $(34.97 \pm 8.67$ vs. 34.57 $\pm 8.16, p=0.835$ ), and the ANOVA eventually disclosed a significant difference when taking in account both gender and qualification $(p=0.105)$. Interestingly enough, PA estimates were also higher in older participants $(>35 \mathrm{yr}$ of age at the time of the survey; i.e. $37.88 \pm 9.01$ vs. $35.29 \pm$ $8.79, p=0.027)$, and particularly among participants performing administrative/social jobs (38.21 \pm 6.60 vs. 33.63 $\pm 8.54, p=0.036$ ), while in the subset of emergency workers the estimates were somewhat similar $(37.70 \pm 9.52$ in older age groups compared to $36.52 \pm 8.82, p=0.375)$, and ANOVA reported no significant differences in-between the subsets $(p=0.226)$.

In regression analysis (Table 3), female gender was 
Table 2. Comparison of the three dimensions of burnout syndrome among 241 first aid volunteers (FAVs), from Salerno province (Campania, Southern Italy; 2019)

\begin{tabular}{|c|c|c|c|c|c|c|c|c|c|}
\hline & \multicolumn{3}{|c|}{ Emotional exhaustion } & \multicolumn{3}{|c|}{ Depersonalization } & \multicolumn{3}{|c|}{ Personal accomplishment } \\
\hline & $\begin{array}{l}\text { Total sample } \\
\text { (No. 241) }\end{array}$ & $\begin{array}{c}\text { Emergency } \\
\text { duties } \\
\text { (No. 162) }\end{array}$ & $\begin{array}{l}\text { Admin. / } \\
\text { Social jobs } \\
\text { (No.79) }\end{array}$ & $\begin{array}{c}\text { Total } \\
\text { sample } \\
\text { (No. 241) }\end{array}$ & $\begin{array}{c}\text { Emergency } \\
\text { duties } \\
\text { (No. 162) }\end{array}$ & $\begin{array}{l}\text { Admin./ } \\
\text { Social jobs } \\
(\text { No. } 79)\end{array}$ & $\begin{array}{l}\text { Total sample } \\
\text { (No. 241) }\end{array}$ & $\begin{array}{c}\text { Emergency } \\
\text { duties } \\
\text { (No. 162) }\end{array}$ & $\begin{array}{c}\text { Admin. / } \\
\text { Social jobs } \\
\text { (No.79) }\end{array}$ \\
\hline \multicolumn{10}{|l|}{ Gender } \\
\hline Women & $5.84 \pm 7.99$ & $6.87 \pm 9.08$ & $3.78 \pm 4.56$ & $3.96 \pm 4.56$ & $4.57 \pm 4.93$ & $2.74 \pm 3.42$ & $35.06 \pm 9.13$ & $35.30 \pm 9.60$ & $34.57 \pm 8.16$ \\
\hline Men & $4.54 \pm 5.49$ & $4.93 \pm 6.22$ & $3.73 \pm 4.24$ & $2.90 \pm 3.46$ & $3.07 \pm 3.50$ & $2.55 \pm 3.40$ & $38.15 \pm 8.43$ & $39.67 \pm 7.94$ & $34.97 \pm 8.67$ \\
\hline $\begin{array}{l}\text { Student's t-test } \\
p \text { value }\end{array}$ & 0.133 & 0.128 & 0.951 & 0.041 & 0.025 & 0.804 & 0.007 & 0.002 & 0.835 \\
\hline $\begin{array}{l}\text { Two-way ANOVA } \\
p \text { value }\end{array}$ & & 0.331 & & & 0.253 & & & 0.105 & \\
\hline \multicolumn{10}{|l|}{ Age groups } \\
\hline $18-35 \mathrm{yr}$ & $5.18 \pm 7.34$ & $6.36 \pm 8.86$ & $3.60 \pm 4.11$ & $3.24 \pm 3.92$ & $3.68 \pm 4.21$ & $2.65 \pm 3.43$ & $35.29 \pm 8.79$ & $36.52 \pm 8.82$ & $33.63 \pm 8.54$ \\
\hline$>35 \mathrm{yr}$ & $5.45 \pm 6.68$ & $5.73 \pm 7.13$ & $4.26 \pm 4.19$ & $3.90 \pm 4.46$ & $4.19 \pm 4.66$ & $2.68 \pm 3.35$ & $37.88 \pm 9.01$ & $37.80 \pm 9.52$ & $38.21 \pm 6.60$ \\
\hline $\begin{array}{l}\text { Student's t-test } \\
p \text { value }\end{array}$ & 0.774 & 0.619 & 0.550 & 0.237 & 0.469 & 0.969 & 0.027 & 0.375 & 0.036 \\
\hline $\begin{array}{l}\text { Two-way ANOVA } \\
p \text { value }\end{array}$ & & 0.548 & & & 0.710 & & & 0.226 & \\
\hline \multicolumn{10}{|l|}{ Length of service } \\
\hline$\leq 10 \mathrm{yr}$ & $4.46 \pm 5.78$ & $5.20 \pm 6.63$ & $3.76 \pm 4.11$ & $3.08 \pm 3.77$ & $3.53 \pm 4.05$ & $2.66 \pm 3.39$ & $36.61 \pm 8.84$ & $37.89 \pm 8.99$ & $34.73 \pm 8.32$ \\
\hline$>10 \mathrm{yr}$ & $8.15 \pm 10.56$ & $8.15 \pm 10.56$ & N/A & $5.37 \pm 5.15$ & $5.37 \pm 5.15$ & N/A & $35.33 \pm 9.45$ & $35.33 \pm 9.45$ & N/A \\
\hline $\begin{array}{l}\text { Student's t-test } \\
p \text { value }\end{array}$ & 0.033 & 0.083 & & 0.006 & 0.020 & & 0.405 & 0.119 & \\
\hline $\begin{array}{l}\text { Two-way ANOVA } \\
p \text { value }\end{array}$ & & N/A & & & N/A & & & N/A & \\
\hline \multicolumn{10}{|l|}{ Educational level } \\
\hline Undergraduate & $4.79 \pm 6.33$ & $5.39 \pm 7.16$ & $3.69 \pm 4.22$ & $3.42 \pm 4.11$ & $3.86 \pm 4.39$ & $2.58 \pm 3.40$ & $36.03 \pm 9.18$ & $36.80 \pm 9.47$ & $35.61 \pm 8.49$ \\
\hline Postgraduate & $10.37 \pm 1.89$ & $9.64 \pm 11.19$ & $4.80 \pm 1.92$ & $4.17 \pm 4.48$ & $4.24 \pm 4.71$ & $3.80 \pm 3.49$ & $38.73 \pm 6.83$ & $39.16 \pm 7.09$ & $36.60 \pm 5.31$ \\
\hline $\begin{array}{l}\text { Student's t-test } \\
p \text { value }\end{array}$ & 0.045 & 0.077 & 0.299 & 0.395 & 0.707 & 0.44 & 0.059 & 0.155 & 0.608 \\
\hline $\begin{array}{l}\text { Two-way ANOVA } \\
p \text { value }\end{array}$ & & 0.373 & & & 0.686 & & & 0.935 & \\
\hline
\end{tabular}

Comparisons by gender, age group ( $18-35 \mathrm{yr}$ vs. $>35 \mathrm{yr}$ ), length of service $(\leq 10 \mathrm{yr}$ vs. $>10 \mathrm{yr})$, educational level (undergraduate vs. graduate) were initially performed by means of Student's $t$-test for unpaired data. A two-way ANOVA was then modeled taking in account the qualification (i.e. FAVs performing emergency duties vs. FAVs performing administrative/social jobs).

acknowledged as the only negative predictor for the BOS dimension of PA (B $-0.250,95 \%$ CI -0.453 to -0.047 , $p=0.016$ for the sample as a whole; $\mathrm{B}-0.303,95 \% \mathrm{CI}$ -0.566 to $-0.040, p=0.024)$. In facts, all analysis were characterized by very low values of Nagelkerker's $\mathrm{R}^{2}$, the statistical measure that represents the proportion of the variance for an outcome variable that's explained by independent variables, with an estimate of $0.013,0.034$, and 0.026 for EE, DP and PA, respectively, i.e. only $1.3 \%$, $3.4 \%$ and $2.6 \%$ of the observed variation can be explained by the model's inputs.

\section{Discussion}

Our study shows that the mental problems that characterize BOS are not absent in volunteers. In our crosssectional study, significant differences were found by gender, i.e., higher levels of EE and DP in females, age and level of experience. Length of service with more than $10 \mathrm{yr}$ was also associated with higher levels of EE and DP in the overall sample of Red Cross volunteers.

More precisely, emotional exhaustion and depersonalization were higher, and personal accomplishment lower, in FAVs engaged in emergency duties than among volunteers engaged in social and administrative activities. 
Table 3. Predictors of burnout syndrome (BOS) among 241 First Aid Volunteers (FAVs) participating into the survey

\begin{tabular}{|c|c|c|c|c|c|c|c|}
\hline & \multirow{2}{*}{$\begin{array}{l}\text { Dimension of BOS } \\
\text { Factor }\end{array}$} & \multicolumn{3}{|c|}{ All participants } & \multicolumn{3}{|c|}{ Subset of emergency workers } \\
\hline & & B & $95 \% \mathrm{CI}$ & $p$ value & B & $95 \% \mathrm{CI}$ & $p$ value \\
\hline \multirow[t]{6}{*}{ EE } & (Constant) & 0.913 & $0.624 ; 1.203$ & $<0.001$ & 0.936 & $0.457 ; 1.415$ & $<0.001$ \\
\hline & Female gender & -0.082 & $-0.192 ; 0.029$ & 0.148 & -0.132 & $-0.301 ; 0.037$ & 0.125 \\
\hline & Age & 0.002 & $-0.003 ; 0.006$ & 0.424 & 0.003 & $-0.004 ; 0.009$ & 0.388 \\
\hline & Years as emergency workers & 0.005 & $-0.005 ; 0.014$ & 0.342 & -0.021 & $-0.015 ; 0.012$ & 0.824 \\
\hline & Educational achievement & 0.054 & $-0.035 ; 0.144$ & 0.234 & 0.067 & $-0.069 ; 0.203$ & 0.331 \\
\hline & Nagelkerker's $\mathrm{R}^{2}$ & 0.013 & & & 0.002 & & \\
\hline \multirow[t]{6}{*}{ DP } & (Constant) & 1.276 & $0.781 ; 1.770$ & $<0.001$ & 1.407 & $0.667 ; 2.137$ & $<0.001$ \\
\hline & Female gender & -0.179 & $-0.369 ;-0.010$ & 0.063 & -0.207 & $-0.464 ; 0.051$ & 0.115 \\
\hline & Age & 0.006 & $-0.001 ; 0.013$ & 0.117 & 0.006 & $-0.003 ; 0.016$ & 0.182 \\
\hline & Years as emergency workers & 0.008 & $-0.008 ; 0.025$ & 0.313 & 0.001 & $-0.020 ; 0.021$ & 0.956 \\
\hline & Educational achievement & 0.026 & $-0.128 ; 0.180$ & 0.74 & 0.013 & $-0.194 ; 0.220$ & 0.903 \\
\hline & Nagelkerker's $\mathrm{R}^{2}$ & 0.034 & & & 0.014 & & \\
\hline \multirow[t]{6}{*}{ PA } & (Constant) & 2.072 & & $<0.001$ & 1.671 & $0.925 ; 2.417$ & $<0.001$ \\
\hline & Female gender & -0.250 & $-0.453 ;-0.047$ & 0.016 & -0.303 & $-0.566 ;-0.040$ & 0.024 \\
\hline & Age & 0.000 & $-0.007 ; 0.007$ & 0.941 & 0.002 & $-0.008 ; 0.012$ & 0.565 \\
\hline & Years as emergency workers & 0.002 & $-0.015 ; 0.019$ & 0.83 & 0.003 & $-0.017 ; 0.024$ & 0.739 \\
\hline & Educational achievement & -0.126 & $-0.291 ; 0.039$ & 0.133 & -0.041 & $-0.252 ; 0.171$ & 0.705 \\
\hline & Nagelkerker's $\mathrm{R}^{2}$ & 0.026 & & & 0.030 & & \\
\hline
\end{tabular}

Two distinctive models were assessed, initially by assessing the sample as a whole (No. 241), and then by analyzing the subset of FAV performing emergency service (i.e. "emergency workers"). EE: Emotional exhaustion; DP: depersonalization; PA: personal achievement.

In multivariate analysis, length of service was confirmed as the only predictor of EE and DP in the sample considered as a whole, but not in the sub-sample of emergency volunteers.

The higher levels of BOS among volunteers performing emergency assistance, confirm the existing association between emergency jobs and BOS previously described in literature ${ }^{51,52)}$. A qualitative study on 14 professionals and 11 volunteer ambulance rescuers of the Italian Red Cross showed frequent exposure to highly challenging situations and higher anxiety levels among volunteers ${ }^{53)}$.

However, in our study the prevalence of burnout and sub-dimensions scores was rather low if compared to levels of BOS reported by a meta-analysis showing that $40 \%$ emergency medicine physicians experience high levels of emotional exhaustion and depersonalization ${ }^{54)}$.

In facts, FAVs who support emergency healthcare professionals are requested to protect and assist the patients and/or driving the ambulance ${ }^{55}$, and all these duties could obviously lead to burnout and other mental health outcomes, even if no universal consent has been reached on the evaluation of the susceptibility to burnout in social and welfare volunteers ${ }^{56}$, and particularly on its dimensions. For instance, Gabassi et al. ${ }^{57)}$, have focused on the differences in susceptibility to burnout between volunteers and professional operators, and volunteers scored lower median ratings of exhaustion and reduced personal accomplishment than professionals, probably due to their job motivation. On the contrary, a literature review on volunteers from the healthcare settings hinted that both volunteers and regular staff are usually subject to high levels of depersonalization, but FAVs apparently do not differ from the norm in susceptibility to emotional exhaustion and self-realization ${ }^{58,59)}$. On the contrary, according to Vecina et al. ${ }^{60)}$ and Ripamonti et al. ${ }^{56)}$, carrying on a volunteering activity for a long time can trigger high levels of emotional exhaustion which, according to Maslach's model ${ }^{6}$, often is the first step in the process leading to burnout syndrome. Not coincidentally, also in our study, volunteering in healthcare assistance was associated with higher level of both emotional exhaustion and depersonalization than volunteering in administrative duties, i.e., activities that are only marginally associated with emotional triggers of BOS. Higher level of DP than EE in our study, confirms the model by Golembiewsky et $a l .{ }^{61)}$, in which depersonalization leads to a reduction in self-satisfaction and finally to emotional exhaustion.

Pardess has highlighted the fundamental role of an adequate formation of volunteers in preventing stress and burnout ${ }^{62)}$. Healthcare staff are at high risk of mental 
health problems, and this could affect also volunteers employed in emergency activities ${ }^{17,52,63-66)}$. Therefore, healthcare managers need to proactively take steps to protect their mental wellbeing ${ }^{67)}$. Burnout, indeed, has been associated with deleterious effects on both healthcare workers and the quality of their work ${ }^{68)}$. However, very little attention has been given on the critical issue of volunteer burnout. When burnout affects healthcare workers, both their well-being and care of patients may be at risk ${ }^{69)}$.

Furthermore, emotional exhaustion in emergency responders has been linked to a significant increased suicide risk $^{70)}$, secondary traumatic stress ${ }^{71)}$ and compassion fatigue, which results from exposure to a traumatized individual and is described as the convergence of secondary traumatic stress (STS) and cumulative burnout (BO $)^{4)}$.

Likewise, volunteers employed in emergency should be considered in the same way and, therefore, they should require preventive measures through mandatory occupational health and safety regulations, including tailored interventions such as health surveillance and specific training and formation on the basis of type of job and length of service. The prevalence of BOS volunteers in this study, which was lower than other studies, could be in part explained by the preventive work effectively performed by the Red Cross health service department by permanent training services direct to volunteers and provided by occupational health physicians and psychologists. In Italy, the Red Cross organization has a working team of volunteers and psychological experts who provide volunteers with support programmes in coping and resilience within the framework of the psychology of emergency. Therefore, regular health surveillance programmes on workers employed at Italian Red Cross could have maintained sufficient level of mental well-being among staff and volunteers, as shown in our sample ${ }^{65,72)}$. Moreover, nonstandard job motivation in volunteers in perceiving their work as a "vocation", could be a protective factor against BOS and should be took into account ${ }^{61)}$.

This lack of evidence is particularly frustrating when applied the Italian settings, where formal volunteering in healthcare is a nation-wide phenomenon since the end of 19th century, and a large number of lay volunteers carry out their activity for social welfare and healthcare services, either in hospital and community settings.

This study has some limitations. The cross-sectional design of the research prevented us from infer any causal relationship between ambulance volunteering work and burnout syndrome. Other studies have also considered some potential sources of burnout in emergency ambu- lance workers, such as personality characteristics ${ }^{73)}$ and exposure to violence ${ }^{30}$ ), that we have not included in this research. In addition, only a few of socio-demographic characteristics were included in our prediction model.

However, there are also some strengths in this work, that is one of the few carried out among volunteers of the Red Cross. Therefore, we believe that our study could pave the way to further and in-depth research, that should take into consideration the moderating role on the relationship between verbal/physical violence, job stressors and BOS played by organization and context of volunteering $^{74)}$, which are often neglected, and the important role of traits of personality ${ }^{75)}$, as well as of self-efficacy ${ }^{76,77)}$ and self-esteem in the onset of BOS, which is prominent in emergency healthcare as much as in non-healthcare volunteers as well.

\section{Conclusion}

In conclusion, our study found that volunteers of the Red Cross engaged in emergency care reported higher levels of emotional exhaustion and depersonalization and lower level of personal accomplishment than volunteers from the same organization who are engaged in nonhealthcare assistance activities. This shows the need to consider the risk of BOS in non-healthcare volunteers employed in healthcare activities and the need to protect this category of helping profession through work organization interventions on the categories at highest risk (particularly on women and veterans), occupational health surveillance programmes and psychological and debriefing emergency services.

\section{CRediT Authorship Contribution Statement}

Francesco Chirico: Conceptualization, Methodology, Investigation, Writing - original draft, editing, Supervision. Pietro Crescenzo and Serena Ripa: Data collection, Investigation, Data curation. Angelo Sacco, Matteo Riccò: Data analysis, Methodology. Gabriella Nucera: Conceptualization, Writing - review \& editing. Nicola Magnavita: review \& editing.

\section{References}

1) World Health Organization (2019) Burn-out an "Occupational phenomenon": International Classification of Diseases. World Health Organization, Geneva.

2) Lin PY, Wang JY, Shih DP, Kuo HW, Liang WM (2019) 
The interaction effects of burnout and job support on Peptic Ulcer Disease (PUD) among firefighters and policemen. Int J Environ Res Public Health 16, 2369. [Medline] [CrossRef]

3) Chirico F, Nucera G, Magnavita N (2020) Protecting the mental health of healthcare workers during the COVID-19 emergency. BJPsych Int, 1-2. [CrossRef]

4) Cocker F, Joss N (2016) Compassion fatigue among healthcare, emergency and community service workers: a systematic review. Int J Environ Res Public Health 13, 618. [Medline] [CrossRef]

5) Zhang YY, Han WL, Qin W, Yin HX, Zhang CF, Kong C, Wang YL (2018) Extent of compassion satisfaction, compassion fatigue and burnout in nursing: a meta-analysis. J Nurs Manag 26, 810-9. [Medline] [CrossRef]

6) Maslach C, Jackson SE (1981) The measurement of experienced burnout. J Organ Behav 2, 99-113. [CrossRef]

7) Maslach C, Schaufeli WB, Leiter MP (2001) Job burnout. Annu Rev Psychol 52, 397-422. [Medline] [CrossRef]

8) Chirico F (2017) Is it time to consider burnout syndrome an occupational disease? Br J Psych 190,1 e-letter. http:// bjp.rcpsych.org/content/190/1/81.2.e-letters\#is-it-timeto-consider-Burnout-syndrome-an-occupational-disease. Accessed November 24, 2020.

9) Chirico F (2017) [Is burnout a syndrome or an occupational disease? Instructions for occupational physicians]. Epidemiol Prev 41, 294-8 (in Italian). [Medline]

10) Chirico F (2016) Adjustment disorder as an occupational disease: our experience in Italy. Int J Occup Environ Med 7, 52-7. [Medline] [CrossRef]

11) Chirico F (2017) Burnout and depression are not the same thing. Br J Psych 190,1 e-letter. http://bjp.rcpsych. org/content/190/1/81.2.e-letters\#burnout-syndrome-anddepression-are-not-the-same-thing.

12) Montero-Marin J, Zubiaga F, Cereceda M, Piva Demarzo MM, Trenc P, Garcia-Campayo J (2016) Burnout subtypes and absence of self-compassion in primary healthcare professionals: a cross-sectional study. PLoS One 11, e0157499. [Medline] [CrossRef]

13) Chirico $F$ (2016) Job stress models for predicting burnout syndrome: a review. Ann Ist Super Sanita 52, 443-56. [Medline]

14) Chirico F (2017) Combatting the shortage of physicians to alleviate work-related strain. J Health Soc Sci 2, 239-42.

15) Chirico F (2015) [The assessment of psychosocial risk: only "work-related stress" or something else?]. Med Lav 106, 65-6 (in Italian). [Medline]

16) Chirico $F$ (2017) The forgotten realm of the new and emerging psychosocial risk factors. J Occup Health 59, 433-5. [Medline] [CrossRef]

17) Chirico F, Heponiemi T, Pavlova M, Zaffina S, Magnavita N (2019) Psychosocial risk prevention in a global occupational health perspective. A descriptive analysis. Int J Environ Res Public Health 16, 11. [Medline] [CrossRef]

18) Bridgeman PJ, Bridgeman MB, Barone J (2018) Burnout syndrome among healthcare professionals. Am J Health
Syst Pharm 75, 147-52. [Medline] [CrossRef]

19) The Lancet (2019) Physician burnout: a global crisis. Lancet 394, 93. [Medline] [CrossRef]

20) Reichard AA, Jackson LL (2010) Occupational injuries among emergency responders. Am J Ind Med 53, 1-11. [Medline]

21) Khashaba EO, El-Sherif MA, Ibrahim AA, Neatmatallah MA (2014) Work-related psychosocial hazards among Emergency Medical Responders (EMRs) in Mansoura City. Indian J Community Med 39, 103-10. [Medline] [CrossRef]

22) Benedek DM, Fullerton C, Ursano RJ (2007) First responders: mental health consequences of natural and human-made disasters for public health and public safety workers. Annu Rev Public Health 28, 55-68. [Medline] [CrossRef]

23) Magnavita N (2011) Violence prevention in a small-scale psychiatric unit: program planning and evaluation. Int $\mathrm{J}$ Occup Environ Health 17, 336-44. [Medline] [CrossRef]

24) Magnavita N (2014) Workplace violence and occupational stress in healthcare workers: a chicken-and-egg situationresults of a 6-year follow-up study. J Nurs Scholarsh 46, 366-76. [Medline] [CrossRef]

25) Magnavita N, Heponiemi T (2012) Violence towards health care workers in a Public Health Care Facility in Italy: a repeated cross-sectional study. BMC Health Serv Res 12, 108. [Medline] [CrossRef]

26) Magnavita N, Heponiemi T (2011) Workplace violence against nursing students and nurses: an Italian experience. J Nurs Scholarsh 43, 203-10. [Medline] [CrossRef]

27) Magnavita N, Heponiemi T, Chirico F (2020) Workplace violence is associated with impaired work functioning in nurses: an Italian cross-sectional study. J Nurs Scholarsh 52, 281-91. [Medline] [CrossRef]

28) Magnavita N (2013) The exploding spark: workplace violence in an infectious disease hospital - a longitudinal study. BioMed Res Int 2013, 316358. [Medline] [CrossRef]

29) Jiménez RE, Bachelet VC, Gomolán P, Lefio LÁ, Goyenechea M (2019) Violence and burnout in health care emergency workers in Santiago, Chile: a survey-based cross-sectional study. Int Emerg Nurs 47, 100792. [Medline] [CrossRef]

30) Coskun Cenk S (2018) An analysis of the exposure to violence and burnout levels of ambulance staff. Turk J Emerg Med 19, 21-5. [Medline] [CrossRef]

31) Acquadro Maran D, Varetto A, Zedda M, Magnavita $N$ (2017) Violence toward hospital staff and volunteers: a survey of an Italian sample. J Aggress Maltreat Trauma 26.

32) Boland LL, Kinzy TG, Myers RN, Fernstrom KM, Kamrud JW, Mink PJ, Stevens AC (2018) Burnout and exposure to critical incidents in a cohort of emergency medical services workers from Minnesota. West J Emerg Med 19, 987-95. [Medline] [CrossRef]

33) van der Ploeg E, Kleber RJ (2003) Acute and chronic job stressors among ambulance personnel: predictors of 
health symptoms. Occup Environ Med 60 Suppl 1, i40-6. [Medline] [CrossRef]

34) Reardon M, Abrahams R, Thyer L, Simpson P (2020) Review article: prevalence of burnout in paramedics: a systematic review of prevalence studies. Emerg Med Australas 32, 182-9. [Medline] [CrossRef]

35) Molina Y, Dirkes J, Ramirez-Valles J (2017) Burnout in HIV/AIDS volunteers: a socio-cultural analysis among Latino gay, bisexual men, and transgender people. Nonprofit Volunt Sector Q 46, 1231-49. [Medline] [CrossRef]

36) Clubbs BH, Barnette AR, Gray N, Weiner L, Bond A, Harden J, Pineda R (2019) A community hospital NICU developmental care partner program: feasibility and association with decreased nurse burnout without increased infant infection rates. Adv Neonatal Care 19, 311-20. [Medline] [CrossRef]

37) Claxton-Oldfield S (2016) Hospice palliative care volunteers: a review of commonly encountered stressors, how they cope with them, and implications for volunteer training/management. Am J Hosp Palliat Care 33, 201-4. [Medline] [CrossRef]

38) Hayslip B Jr, Sethi A, Pinson MW, Carpenter C (2019) Predicting attrition among hospice volunteers. Omega (Westport) 30222819889830, 30222819889830. [Medline]

39) Willems R, Drossaert C, Vuijk P (2020) Impact of crisis line volunteering on mental wellbeing and the associated factors: a systematic review. Int J Environ Res Public Health 17, 1641. [Medline] [CrossRef]

40) Stehman CR, Testo Z, Gershaw RS, Kellogg AR (2019) Burnout, drop out, suicide: physician loss in emergency medicine, part I. West J Emerg Med 20, 485-94. [Medline] [CrossRef]

41) Li H, Cheng B, Zhu XP (2018) Quantification of burnout in emergency nurses: a systematic review and meta-analysis. Int Emerg Nurs 39, 46-54. [Medline] [CrossRef]

42) Argentero P, Bonfiglio NS, Pasero R (2006) [Burnout in volunteer health workers]. G Ital Med Lav Ergon 28 Suppl 2, 77-82 (in Italian). [Medline]

43) Argentero P, Setti I (2008) Percezione del lavoro, contesti professionali e burnout negli operatori dell'emergenza. G Ital Med Lav Ergon 30, 64-70 (in Italian).

44) Angius P, Campana G, Cattari F, Cattari M, Pirastru S, Tintori A, Serra A (2011) [Burnout in emergency health care workers]. G Ital Med Lav Ergon 33 Suppl, 339-42 (in Italian). [Medline]

45) Ferraro L, La Cascia C, De Santis A, Sideli L, Maniaci G, Orlando IM, Chifari A, Maniaci L, La Barbera D (2020) A cross-sectional survey on burnout prevalence and profile in the Sicilian population of ambulance driver-rescuers. Prehosp Disaster Med 35, 133-40. [Medline] [CrossRef]

46) Istituto Nazione di Statistica (ISTAT) (2017) Censimento permanente delle Istituzioni non profit. Primi risultati. Istituto Nazione di Statistica, Roma.

47) Croce Rossa Italiana. http://www.cri.it/.
48) World Medical Association (2013) World Medical Association Declaration of Helsinki: ethical principles for medical research involving human subjects. JAMA 310, 2191-4. [Medline] [CrossRef]

49) Sirigatti S, Stefanile C (1993) The Maslach Burnout Inventory: Adattamento e taratura per l'Italia. Os, Organizzazioni Speciali, Firenze.

50) Dyrbye LN, West CP, Shanafelt TD (2009) Defining burnout as a dichotomous variable. J Gen Intern Med 24, 440, author reply 441. [Medline] [CrossRef]

51) Schneider A, Weigl M (2018) Associations between psychosocial work factors and provider mental well-being in emergency departments: a systematic review. PLoS One 13, e0197375. [Medline] [CrossRef]

52) Chirico F, Nucera G (2020) Tribute to healthcare operators threatened by COVID-19 pandemic. J Health Soc Sci 5, $165-8$.

53) Sartori RDG, Delle Fave A (2014) First-aid activities and well-being: the experience of professional and volunteer rescuers. J Soc Serv Res 40, 242-54. [CrossRef]

54) Zhang Q, Mu MC, He Y, Cai ZL, Li ZC (2020) Burnout in emergency medicine physicians: a meta-analysis and systematic review. Medicine (Baltimore) 99, e21462. [Medline] [CrossRef]

55) Vanni D, Palasciano G, Vanni P, Vanni S, Guerin E (2018) Medical doctors and the foundation of the International Red Cross. Intern Emerg Med 13, 301-5. [Medline] [CrossRef]

56) Ripamonti CA, Pasquarelli L, Ravasi S, Sala FC (2017) Dropout of hospital volunteers in Italy. Voluntas 28, 44-68. [CrossRef]

57) Gabassi PG, Cervai S, Rozbowsky P, Semeraro A, Gregori D (2002) Burnout syndrome in the helping professions. Psychol Rep 90, 309-14. [Medline] [CrossRef]

58) Galati D, Fassio O, Viglino M (2004) Motivazioni ed emozioni dei medici e degli infermieri del Pronto Soccorso. Nuove Tendenze Psicol 2, 392-412.

59) Ross MW, Greenfield SA, Bennett L (1999) Predictors of dropout and burnout in AIDS volunteers: a longitudinal study. AIDS Care 11, 723-31. [Medline] [CrossRef]

60) Vecina M, Marta E, Pozzi M, Marzana D (2010) What do sustain our will to volunteer? A crosscultural Italian and Spanish comparison. In Close relationships and community psychology: an international perspective, Cigoli $\mathrm{V}$ and Gennari M (Eds.), 118-132, Franco Angeli, Milano.

61) Golembiewsky RT, Munzenrider RF, Stevenson JG (1986) Stress in organizations. Praeger, New York.

62) Pardess E (2005) Training and mobilizing volunteers for emergency response and long-term support. J Aggress Maltreat Trauma 10, 609-20. [CrossRef]

63) Chirico F, Nucera G, Magnavita N (2020) COVID-19: protecting healthcare workers is a priority. Infect Control Hosp Epidemiol 41, 1117. [Medline] [CrossRef]

64) Magnavita N, Sacco A, Nucera G, Chirico F (2020) First aid during the COVID-19 pandemic. Occup Med (Lond) 70, 458-60. [Medline] [CrossRef] 
65) Chirico F, Magnavita N (2021) The crucial role of occupational health surveillance for health-care workers during the COVID-19 pandemic. Workplace Health Saf 69, 5-6. [Medline] [CrossRef]

66) Chirico F, Magnavita N (2020) COVID-19 infection in Italy: an occupational injury. S Afr Med J 110, 12944. [Medline]

67) Greenberg N, Docherty M, Gnanapragasam S, Wessely S (2020) Managing mental health challenges faced by healthcare workers during COVID-19 pandemic. BMJ 368, m1211. [Medline] [CrossRef]

68) Shah K, Chaudhari G, Kamrai D, Lail A, Patel RS (2020) How essential is to focus on physician's health and burnout in coronavirus (COVID-19) pandemic? Cureus 12, e7538. [Medline]

69) Chew FS, Mulcahy MJ, Porrino JA, Mulcahy H, Relyea-Chew A (2017) Prevalence of burnout among musculoskeletal radiologists. Skeletal Radiol 46, 497-506. [Medline] [CrossRef]

70) Edwards DL, Wilkerson ND (2020) Emotional exhaustion and its relationship with suicide risk in emergency responders. Psychiatry Res 293, 113379. [Medline] [CrossRef]

71) Greinacher A, Derezza-Greeven C, Herzog W, Nikendei C (2019) Secondary traumatization in first responders: a systematic review. Eur J Psychotraumatol 10, 1562840. [Medline] [CrossRef]
72) Zuliani A (2017) Azioni e reazioni nell'emergenza. Tutto quello che si deve sapere sui comportamenti umani per costruire un piano di emergenza. EPC editore, Roma (in Italian).

73) Bergmueller A, Zavgorodnii I, Zavgorodnia N, Kapustnik W, Boeckelmann I (2016) [The correlation between personality characteristics and burnout syndrome in emergency ambulance workers]. Zh Nevrol Psikhiatr Im S S Korsakova 116, 25-9. (in Russian). [Medline] [CrossRef]

74) Lasalvia A, Tansella M (2011) Occupational stress and job burnout in mental health. Epidemiol Psychiatr Sci 20, 279-85. [Medline] [CrossRef]

75) Bakker AB, Van der Zee KI, Lewig KA, Dollard MF (2006) The relationship between the Big Five personality factors and burnout: a study among volunteer counselors. J Soc Psychol 146, 31-50. [Medline] [CrossRef]

76) Cherniss C (1993) Role of professional self-efficacy in the etiology and amelioration of burnout. In: Schaufeli WB, Maslach C, Marek T (Eds.), Series in applied psychology: social issues and questions. Professional burnout: recent developments in theory and research, 135-149. Taylor \& Francis, Philadelphia.

77) Shoji K, Cieslak R, Smoktunowicz E, Rogala A, Benight CC, Luszczynska A (2016) Associations between job burnout and self-efficacy: a meta-analysis. Anxiety Stress Coping 29, 367-86. [Medline] [CrossRef] 